\title{
1. Strategic human capital at the crossroads
}

\subsection{PERSPECTIVES ON STRATEGIC HUMAN CAPITAL}

Despite the almost obvious acknowledgment of the role and the relevance of human capital in the context of economic and managerial processes, there exists - according to distinguished scholars (Ployhart \& Moliterno, 2011; Wright, Coff, \& Moliterno, 2014) - a significant divide in the way this fundamental resource has been investigated with respect to a number of issues, such as organizational processes, knowledge development, managerial decision making, and its contribution to firms' competitive advantage.

A major limitation in the investigation of human capital is constituted by the sharp division characterizing both theoretical advances and empirical efforts concerning the level of analysis, as scholars have adopted a rather polarized model, either focusing on the micro level (e.g., the study of individual human resources traits in the context of organizational processes) or on the macro level (that is, the analysis of aggregate human capital at the firm level through the theoretical lens of competences and capabilities). This sharp divide has generated two highly segmented research domains, each characterized by specific languages, approaches, and research methods that, however, have not helped scholars and managers achieve a unifying framework with regard to the important resource that constitutes the central topic of this book human capital.

To fill this void and to reconcile the above two approaches, we maintain that scholars should pay attention to a series of either unaddressed or overlooked issues, such as:

- the importance of a unifying framework for dealing with human capital as an organizational-level resource; 
- the relevance of a meso level in human capital resource management; and

- a fine-grained understanding of the contribution of human capital to organizational performance and competitive advantage.

In this volume, we try to address these issues and take on the challenge of providing a unifying perspective on strategic human capital. We maintain that our effort represents a useful research endeavor for both the theoretical and the managerial perspectives. In particular, we suggest that human capital resources are an extremely valuable asset in the life of every type of organization and that not addressing the above issues could hamper our understanding of the actual contribution of human capital to economic and managerial processes, at different levels of analysis, because this important resource has been investigated through several different lenses. Therefore, given that the diversity of conceptual frameworks and approaches existing in the whole human capital literature - as noted in the Preface - has engendered a number of ambiguities and inconsistencies, we aim to successfully address these ambiguities and inconsistencies in this volume.

\subsection{OVERCOMING THEORETICAL INCONSISTENCIES}

Human resources are the main source of competitive advantage, especially in highly competitive settings, where a bundle of valuable resources becomes central to firm success (Barney, 1991; Peteraf, 1993). Given its relevance as a source of superior performance, several studies have tried to analyze antecedents, constructs, and consequences of human resources (Ployhart \& Moliterno, 2011; Ployhart, Nyberg, Reilly, \& Maltarich, 2014; Wright et al., 2014).

In particular, human capital theory has its roots in both economics (Becker, 1964) and psychology (Spearman, 1927) and represents one of the main approaches to the analysis of human resources as a source of superior firm performance. Management studies have recurrently drawn from this research perspective to understand the contribution of human resources at both the individual and the organizational levels.

Human resources, though, have been observed and investigated in several research fields, following different paths. For example, according to Ployhart and Moliterno (2011), in the context of management studies, two main approaches deal with human resources as a source of competi- 
tive advantage - the micro- and macro-level approaches. More precisely, research in human resources (HR), organizational behavior (OB), and industrial organizations (IO) has focused on the micro level through the analysis of knowledge, skills, and abilities owned by individuals, and of their link with individual-level performance (Ployhart \& Moliterno, 2011; Schmidt \& Hunter, 1998). On the other hand, organization and strategy fields have focused on the macro level by means of the analysis of knowledge, skills, and abilities aggregated at the organizational higher level, and on their contribution to competitive advantage (Barney, 1991; Penrose, 1959; Peteraf, 1993; Ployhart \& Moliterno, 2011).

This difference in the level of analysis has played an important role in the theoretical development of human capital, thus affecting the comprehension of the antecedents, consequences, and dimensions of the human capital construct. These different perspectives affected, in turn, the theoretical issues of interest (such as individual conduct, HR practice, organizational behavior, and so on), research methodologies, the selection of empirical measures, and sources of data. In particular, micro-level studies, instead, focused mainly on the link between individual characteristics and job performance and, because individual characteristics must be measured too, reliability and construct validity are the cornerstone of methodologies adopted for this purpose. Macro-level studies, instead, have relied on different methodologies, mostly through an extensive use of econometrics, thus focusing on longitudinal archival data as a primary source of information (Wright et al., 2014).

However, a specific level of analysis (either at the micro or at the macro level) is doomed to lead to a partial explanation and understanding of the phenomena of interest, since those studies that adopted a micro-level approach did not consider how individual characteristics contribute to competitive advantage, while studies at the macro level neglected the analysis of the acquisition and nurturing of valuable human resources in the context of human capital generation and development, given that their focus was, mainly, on resource heterogeneity and its influence on firm performance. Furthermore, this neglect has given rise to the critique that, from the macro-level perspective, a firm is a black box (Mahoney, 1995; Priem \& Butler, 2001; Van de Ven \& Polley, 1992), a theoretical issue that requires a deeper understanding of resources' microfoundation. In summary, it seems that in the last three decades a quite broad divide has affected the fields of research interested in the contribution of human resources and human capital to organizational results. 
To overcome this separation, a new area of interest has emerged. Defined as strategic human resource management (SHRM), its main focus is on "the pattern of planned human resource deployments and activities intended to enable the firm to achieve its goals" (Wright \& McMahan, 1992, p. 298). From this viewpoint, the SHRM domain deals with "the determinants of decisions about HR practices, the composition of human capital resource pool, the specification of the required human resource behaviours, and the effectiveness of these decisions given various business strategies and/or competitive situations" (Wright \& McMahan, 1992, p. 298).

Despite the breadth of the issues covered by the above statement, this approach has left some theoretical inconsistencies unaddressed, mostly because it suggested that the main purpose of SHRM research was an advance in the understanding of the link between HR practice and job performance, rather than the development of the human capital construct. This research perspective has been subsequently buttressed by empirical studies showing how HR practices positively affect firm performance (Combs, Liu, Hall, \& Ketchen, 2006; Huselid, 1995). In particular, these studies focused on the development of a high-performance system that, by means of the exploitation of individual knowledge, skills, abilities, and other characteristics (KSAOs), investigate how firms achieve competitive advantage. However, the studies failed to investigate the dynamics that lead to resource creation at unit level (Ployhart \& Moliterno, 2011). For example, are a unit's human resources just an aggregation of individual characteristics? This question has not been answered, yet.

In essence, because a full integration of the two research perspectives has not been reached, some issues have remained unexplored, such as the dynamics that lead to the creation of valuable resources at the firm level, a void that affects, in turn, the understanding of what should be the appropriate endowment of resources for competitive purpose. This is because micro-level studies focus on how individual characteristics affect the ability to perform a specific task and assume this ability as an antecedent of firm performance. However, this approach fails to explain how these individual characteristics interact with other human resources, culture, strategy, and experience embedded in a given firm, nor does it provide a clear examination of how middle managers interact with other human resources at the individual level. On the other hand, macro-level research focuses on higher-level dynamics based on aggregate human resources conceived of as a bundle of individuals. However, this research 
perspective too omits to explain how resources are shaped at higher levels, and how middle managers contribute to this purpose.

In sum, human resources available for firms' purposes are treated, in many studies, as the sum of the individual KSAOs, thus neglecting the interaction with other human resources already present and embedded in the organization. This neglect implies that the way in which both cognitive and non-cognitive levels of experience and skills are combined requires further exploration. In particular, scholars, experts, and managers are not provided with a conceptual framework for addressing their specific professional needs with respect to the consequences of many crucial decisions in the context of human resource endowment. This is because the understanding of how resources combine and aggregate within the organization, starting from the initial KSAO endowment, is still limited. More precisely, we maintain that the dynamics concerning the evolution of human resource endowment at the organizational level requires further examination with regard to, in particular, renewal choices of human capital under the specific circumstances of an organization's short- and long-term needs.

We maintain that the analysis of the interactions between renewal choices and the initial endowment of human capital can lead to an important advance in the understanding of resource development at the unit level (Kozlowski \& Klein, 2000; Ployhart et al., 2014). This implies, in turn, the integration of the micro- and the macro-level approaches into a holistic research framework that includes the meso level too, in order to explain higher-order resources generation and their relationship with organizational performance.

Figure 1.1 reports the evolution of the two different research approaches so far considered, (i.e., psychology and economics perspectives), whose convergence in the SHRM framework, although useful and influential, falls far short of scholars' and managers' expectations with regard to a compelling unifying approach.

A major limitation of the convergence of the above-mentioned scholarly perspectives in the SHRM framework involves their juxtaposition, which highlights that they are not fully integrated, an occurrence that affects our comprehension of the processes regarding the acquisition, development, retention, and renewal of human resources at the organizational level. In particular, the gap between these two different perspectives points to the need to define a new research domain to overcome the above limitations and open a dialogue between their diverging topics. 


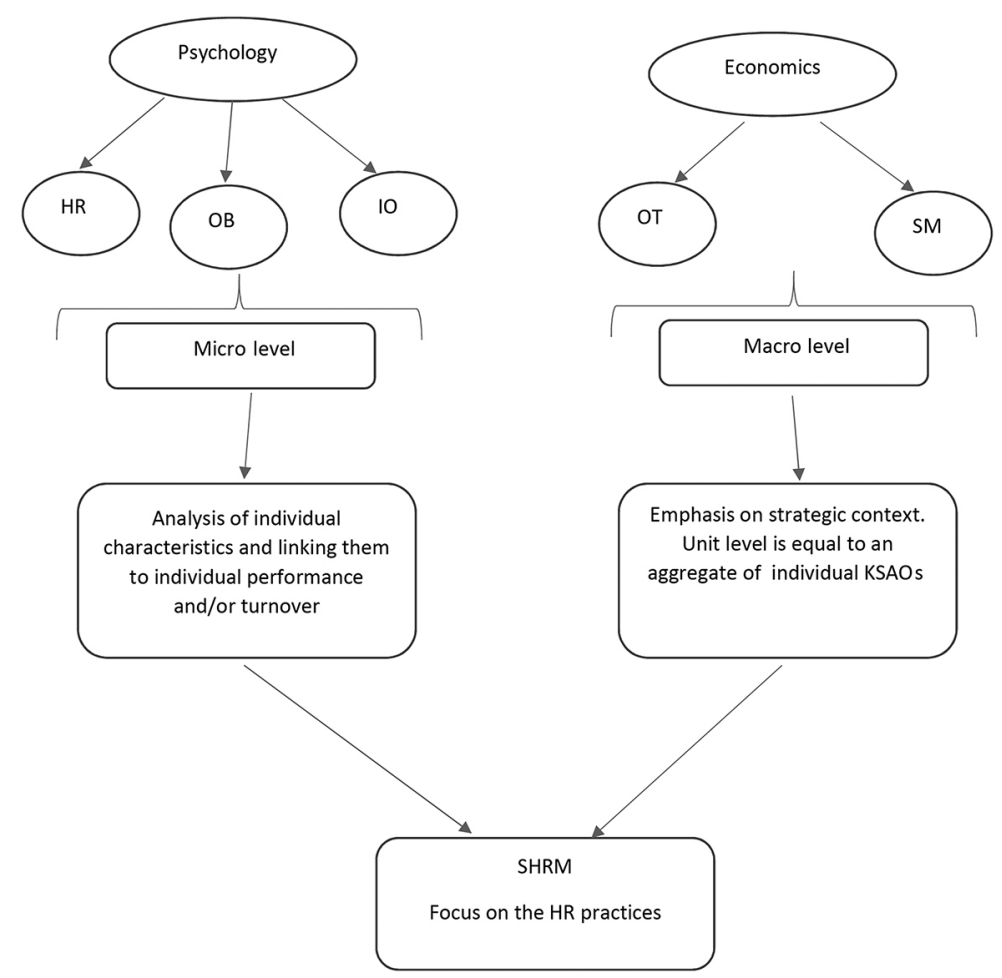

Note: $\quad \mathrm{HR}=$ human resources; $\mathrm{OB}=$ organizational behavior; $\mathrm{IO}=$ industrial organizations; OT = organizational theory; $\mathrm{SM}=$ strategic management.

\section{Figure 1.1 Human capital resource perspectives}

To this end, Wright et al. (2014) call for the development of a common platform and identify several issues on which to build a dialogue between these research fields. In particular, they invite convergence on a specific set of issues, namely, how to assess and define human capital at different levels of analysis; what are the main individual characteristics that can be considered as human capital; why do firms choose a specific investment in human capital instead of other types of investment; what type of human capital is actually strategic for a given firm; what is the role played by firm specificity on value creation; and what are the dynamics that allow for the appropriation of the value generated by strategic human capital. 
Notwithstanding the relevance of these theoretical issues, it seems that our understanding of the human capital domain is hampered by the lack of a unifying definition of its construct and of the related dimensions. For instance, while Campbell, Coff, and Kryscynski (2012) consider human capital as an employer's investment and focus on its relationship with firms' performance, Ployhart and Moliterno (2011) define human capital at unit level as an emergent phenomenon originating from individual KSAOs.

The lack of widespread acceptance of a common construct concerning human capital resources, in turn, implies that there are some basic theoretical issues requiring further conceptual investigation, namely:

- what is human capital;

- what are human capital antecedents; and

- what are the consequences of investments in human capital development.

These basic theoretical points are important because, according to Ployhart et al. (2014), there are many inconsistencies in extant studies that hamper our understanding of human capital at different levels and how it contributes to value creation at the organizational level. Table 1.1 lists the main definitions of human capital resources proposed by Ployhart et al. (2014).

The review of the main contributions on human capital proposed by Ployhart et al. (2014) highlights the absence of a shared framework concerning both the definition and the levels of analysis. This bears important implications with regard to the validity of the human capital resource construct and, in turn, with respect to our understanding of the consequences of a specific combination of resources on a firm's competitive advantage.

To fill this void, Wright et al. (2014) suggest a combination of two dimensions: (1) the level of analysis; and (2) the malleability of individual characteristics. The aim of their framework is to reach a common definition of the human capital construct. This seems a promising advance, since it takes account of the dynamic that generates an increasing value for organizations by introducing different levels of analysis and, also, the link between human resources and firm performance to achieve an advancement from both the theoretical and the empirical standpoints. More precisely, these authors suggest developing SHRM over three levels of analysis: (1) intra-individual level; (2) individual level; and (3) 


\section{Table 1.1 Main definitions of human capital resources}

\begin{tabular}{|c|c|c|c|}
\hline Article & Definition & $\begin{array}{l}\text { Level of } \\
\text { Analysis }\end{array}$ & Disciplinary Origin \\
\hline $\begin{array}{l}\text { Becker }(2002, \\
\text { p. 3) }\end{array}$ & $\begin{array}{l}\text { "Human capital refers to the knowledge, } \\
\text { information, ideas, skills, and health of } \\
\text { individuals" }\end{array}$ & Individual & Economics \\
\hline \multirow[t]{2}{*}{$\begin{array}{l}\text { Coff and } \\
\text { Kryscynski (2011, } \\
\text { p. 1430) }\end{array}$} & $\begin{array}{l}\text { Human capital: "an individual's stock of } \\
\text { knowledge, skills, and abilities" }\end{array}$ & Individual & $\begin{array}{l}\text { Strategy/ } \\
\text { microfoundations }\end{array}$ \\
\hline & $\begin{array}{l}\text { Firm-level human assets: "firm-level } \\
\text { aggregation of employee skills" }\end{array}$ & Firm & Strategy \\
\hline $\begin{array}{l}\text { Crook, Todd, } \\
\text { Combs, Woehr, } \\
\text { and Ketchen } \\
(2011, \text { p. } 444)\end{array}$ & $\begin{array}{l}\text { "The term human capital refers to the } \\
\text { knowledge, skills and abilities (KSAs) } \\
\text { embodied in people" }\end{array}$ & $\begin{array}{l}\text { Firm/ } \\
\text { individual }\end{array}$ & Strategy \\
\hline $\begin{array}{l}\text { Hitt, Biermant, } \\
\text { Shimizu, and } \\
\text { Kochhar (2001, } \\
\text { p. 14) }\end{array}$ & $\begin{array}{l}\text { "Human capital attributes (including } \\
\text { education, experience, and skills) ... of } \\
\text { top managers affect firm outcomes" }\end{array}$ & Firm & Strategy \\
\hline $\begin{array}{l}\text { Huselid, Jackson, } \\
\text { and Schuler } \\
(1997, \text { p. 171) }\end{array}$ & $\begin{array}{l}\text { "Employees' collective knowledge, } \\
\text { skills, and abilities" }\end{array}$ & Firm & $\begin{array}{l}\text { Strategic human } \\
\text { resources } \\
\text { management }\end{array}$ \\
\hline $\begin{array}{l}\text { Kor and Leblebici } \\
(2005, \text { p. } 968)\end{array}$ & $\begin{array}{l}\text { "Firms' strategic human resources } \\
\text { such as professionals with specialized } \\
\text { knowledge and expertise" }\end{array}$ & Firm & Strategy \\
\hline $\begin{array}{l}\text { Ployhart and } \\
\text { Moliterno (2011, } \\
\text { pp. 127-128) }\end{array}$ & $\begin{array}{l}\text { "A unit level resource that is created } \\
\text { from the emergence of individuals' } \\
\text { knowledge, skills, abilities and other } \\
\text { characteristics (KSAOs)" }\end{array}$ & Unit & Psychology/strategy \\
\hline $\begin{array}{l}\text { Somaya, } \\
\text { Williamson, and } \\
\text { Lorinkova (2008, } \\
\text { p. 936) }\end{array}$ & $\begin{array}{l}\text { "Defined broadly as the cumulative } \\
\text { knowledge, skills, talent, and knowhow } \\
\text { of the firm's employees" }\end{array}$ & Firm & $\begin{array}{l}\text { Strategy/ } \\
\text { knowledge-based } \\
\text { view }\end{array}$ \\
\hline
\end{tabular}




\begin{tabular}{llll}
\hline Article & Definition & $\begin{array}{l}\text { Level of } \\
\text { Analysis }\end{array}$ & Disciplinary Origin \\
\hline Wright and & "At the unit level, human capital can & Unit & Strategic human \\
McMahan (2011, & $\begin{array}{l}\text { refer to the aggregate accumulation of } \\
\text { individual human capital that can be }\end{array}$ & & $\begin{array}{l}\text { resources } \\
\text { management }\end{array}$ \\
& $\begin{array}{l}\text { combined in a way that creates value } \\
\text { for the unit" }\end{array}$ & & \\
& "Human capital simply refers to & Individual & Strategic human \\
Youndt and Snell & individual employees' knowledge, & & $\begin{array}{l}\text { resources } \\
\text { (2004, p. 338) }\end{array}$ \\
& skills, and expertise" & management \\
\hline
\end{tabular}

Source: $\quad$ Ployhart et al. (2014), p. 375, Table 1.

unit level. The first level refers to knowledge, skills, abilities, and other traits (KSAOs) owned by individuals. The second level considers the investigation of the dimensions of competitive advantage in which individuals are embedded, and, thanks to which, individual characteristics become "capital" for organizations. Finally, a unit level of analysis is introduced, with the purpose of understanding when individual human capital can be conceived of as a human capital pool (Wright, McMahan, \& McWilliams, 1994).

However, to conceptualize the human capital construct, it seems appropriate to account for the characteristics of individuals, since, as stated by Ployhart and Moliterno (2011), "the origins of human capital resources exist in the full range of KSAOs of employees within the unit" (p. 133). Thus, according to their view, the basic unit of analysis is an individual's KSAOs. This issue is broadly explored by the literature on HR practice with respect to selection methods whose purpose is to match candidate characteristics and company needs by means of employment tests (such as interviews and assessment procedures) with the purpose of measuring abilities, competencies, personality traits, and assessing cognitive and non-cognitive KSAOs and their fit with a company's goals and needs. Especially, with respect to cognitive KSAOs, following Ployhart and Moliterno (2011), we should consider four basic types of ability that, in general terms, reflect what people "can do":

- General cognitive ability (e.g., general mental ability or intelligence, or $g$ [the $g$ factor]) represents KSAOs that involve the comprehension, manipulation, retention, and creation of information (Jensen, 1998). It is relatively stable throughout adulthood and is the strongest predictor of educational and occupational outcomes (Carroll, 1993; Gottfredson, 1997; Jensen, 1998; Schmidt \& Hunter, 1998). 
- Knowledge is an understanding of principles, facts, and processes. Knowledge can range from generic to specific (e.g., knowledge of accounting to knowledge of how to use a particular firm's accounting software). It is usually clustered within domains such as those learned through formal education (e.g., accounting) and/or experience.

- Skills represent a capacity to learn more information or learn information more quickly (e.g., study skills, reading skills). They are tied to generic domains reflecting much of what is learned through formal education or experience (e.g., problem solving, social interactions).

- Experience is a multifaceted construct that reflects an opportunity to learn and transfer knowledge from generic, to job and firm specific. There are multiple types of experience (e.g., job, firm) that vary in terms of amount, time, and type (Quińones, Ford, \& Teachout, 1995). (Cited from Ployhart \& Moliterno, 2011, p. 134, Table 2; original emphasis)

In addition, these authors recognize three types of non-cognitive KSAOs that refer to "will do" abilities: personality, interests, and values (Ployhart \& Moliterno, 2011, 134, Table 2; original emphasis):

- Personality refers to a set of traits, generally stable throughout adulthood, that direct and maintain consistency in behavior. The Five Factor Model (FFM) of personality (McCrae \& Costa, 1996) is dominant and includes emotional stability (resistance to anxiety and stress), extroversion (dominance, social striving), openness to experience (desire to learn and experience new things), agreeableness (empathy and desire to get along with others), and conscientiousness (dependability, achievement, reliability).

- Interests and values are stable throughout adulthood and represent an individual's preferences for certain types of work. The best example of this individual-level noncognitive attribute is Holland's RIASEC ${ }^{1}$ model (1997), which notes that people choose occupations that fit their interests and values.

Non-cognitive KSAOs and general cognitive abilities are stable since they stem from how personality evolves over time and cannot be modified significantly by advances in education and/or experience (Kanfer, 1990). The extant literature considers these characteristics as predictors of job performance and firm performance (Carroll, 1993; Schmidt \& Hunter, 1998). KSAOs become part of an organization when they are combined with those owned by other employees and, thus, become higher-level human resources at the team or unit level.

However, the dynamic that allows for the combination and integration of KSAOs is not yet completely unpacked. To fill this void, the process leading to valuable unit-level human resources consists of two interrelated components. The first is "the complexity of the unit's task envi- 
ronment, or the degree to which the unit's tasks require interdependence and coordination among members" (Ployhart \& Moliterno, 2011, p. 135). The second is defined as "enabling states and consists of the unit's behavioural processes, cognitive mechanisms, and affective psychological states" (Ployhart \& Moliterno, 2011, p. 135).

In detail, with respect to the first component, Ployhart and Moliterno (2011) identify four dimensions that characterize the complexity of the task. The first dimension, temporal pacing, refers to employees' need to interact to complete a given task. This implies that face-to-face interaction is needed because information sharing is not enough. The second dimension is the dynamism of the task environment affecting the processes of organizational resource creation (Eisenhardt \& Martin, 2000; Teece, 2007). Then, task complexity is another dimension of the interaction dynamic that requires the need to communicate with other team members. Finally, they suggest a fourth dimension, workflow structure, defined as "pooled, sequential, reciprocal, and intensive" (Ployhart \& Moliterno, 2011, p. 136), as a feature in the creation of higher-order resources. Considered all together, these characteristics affect the creation of unit-level resources originating from individual KSAOs.

The second component of the process leading to valuable unit-level, emergence enabling states, that is, behavioral, cognitive, and affective, support the development of human resources at unit level, since they facilitate interaction among team members. These features are highly context and firm contingent, since they could be particularly relevant in the performance of some tasks and within some firms, while they could be completely irrelevant in the performance of another task at another company, as highlighted by the literature on the contribution of human resources to organizational performance at a micro level (Coff \& Kryscynski, 2011).

These considerations summon a further characteristic to better investigate the contribution of human resources to competitive advantage, defined by Wright et al. (2014) as "malleability." Although the above characteristics (both cognitive and non-cognitive abilities) can be, to some extent, resistant to change, depending on the degree of malleability individual characteristics can be nurtured and developed over time. This introduces a further dimension in the context of human capital resources practices, especially with respect to their relationship with managerial decisions and, in turn, competitive advantage. More precisely, several strategy scholars have emphasized the relevance of firm-specific, higher-order resources and their contribution to organi- 
zational performance (Barney \& Wright, 1998; Hatch \& Dyer, 2004). In particular, they conceive of these resources as competences and capacities that allow firms to achieve competitive advantage. However, they warn that these resources are characterized by causal ambiguity and, also, non-transferability between and among firms. Furthermore, in order to understand how human resources contribute to competitive advantage at the organizational level, we must consider KSAOs' heterogeneity (Ployhart et al., 2014), since this affects the way human capital resources are combined and, in turn, higher-order resources can be shaped.

In summary, given the different issues emphasized by the examined perspectives, a multidisciplinary framework is needed to analyze the dynamics that allow for the identification of how individual KSAOs are available for units' purposes, along with the processes of combination and interaction among people with heterogeneous competences (Ployhart et al., 2014).

The development of this framework should help overcome the lack of internal consistency that limits the development of a holistic framework, thus providing an important advance to this area of research. To this end, Ployhart et al. (2014) integrate several contributions by decomposing human resources into three elements:

- what human resources are, to define their structure;

- what human resources do, to define their function; and

- the level at which they can be observed.

To contribute to the definition of human resource structure, they distinguish among different constructs proposed by the extant literature, thus clarifying the different levels of analysis. In detail, they define as individual differences the bundle of capacity, both cognitive and non-cognitive, owned by people, such as ability, personality, motivation, attitudes, and physical characteristics (see also Ackerman and Heggestad, 1997; Guion, 2011). However, emotion, motivation, and satisfaction cannot be defined as KSAOs because they are influenced by environmental conditions only those individual characteristics that are relatively stable over time are conceived of as KSAOs. In turn, only those KSAOs that are linked with economic outcome can be defined as human capital (Ployhart et al., 2014).

Finally, human capital resources is defined as a subset of human capital. The distinction between these two constructs (i.e., human capital and human capital resources) is central to the development of a holistic 
theoretical framework and is relevant for the internal consistency of its main construct. Indeed, many studies use these concepts interchangeably, while other scholars state that human capital can exist only at the individual level, and that it cannot be directly available for the purpose of the firm (Nyberg, Moliterno, Hale, \& Lepak, 2014).

By assuming that human capital is just a directly available individual-level resource, and not also a firm-level resource, many theoretical contributions have been overlooked or neglected. In particular, the studies that emphasize the contribution of individual differences of CEOs, top management, and star employees to organizational performance have been almost ignored (Carpenter, Sanders, \& Gregersen, 2001; Groysberg \& Lee, 2009; Hess \& Rothaermel, 2011; Rosen, 1981; Rothaermel \& Hess, 2007; Sanders \& Hambrick, 2007; Zucker and Darby, 1996).

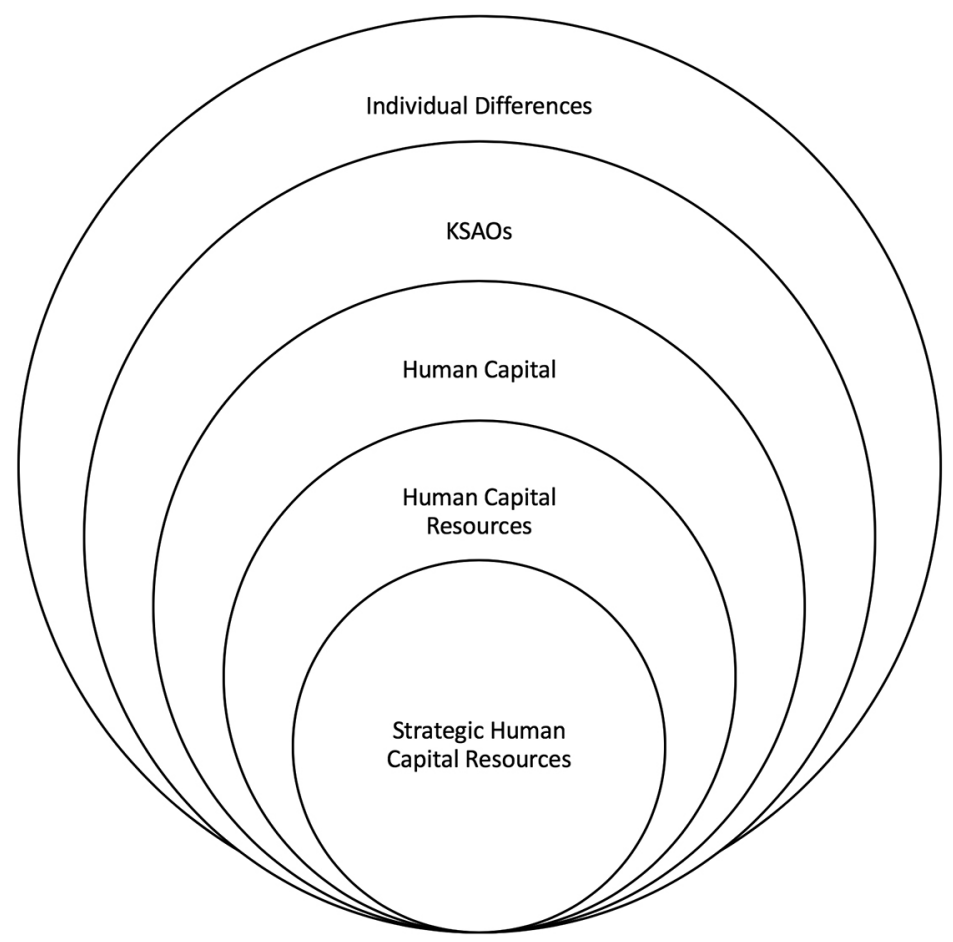

Source: $\quad$ Adapted from Ployhart et al. (2014), p. 375.

Figure 1.2 Human resources constructs 
In summary, human capital resources are those resources available for a unit's purpose (Ployhart et al., 2014) and among these resources a specific subset is strategically relevant in the quest for competitive advantage. In this case, human capital resources become strategic human capital resources. Figure 1.2 represents the distinction between these constructs, as introduced by Ployhart et al. (2014).

The literature examined so far and the model proposed by Ployhart et al. (2014) help us to depict a theoretical framework that improves construct validity of the phenomenon under observation. However, this investigation requires further exploration. In particular, the dynamic leading to the generation of human capital resources at the unit level needs a deeper analysis. More precisely, a tighter examination is required from the initial condition that allows for its generation (that is, the bundle of individual differences) to the final configuration of strategic human capital resources.

By adopting a resource microfoundation perspective, in particular, we can identify how individual capacity can become human capital for the organization, while from a macro perspective it is possible to identify the path to competitive advantage (Barney \& Felin, 2013; Ployhart \& Moliterno, 2011; Ployhart et al., 2014).

\subsection{ADDRESSING NEW METHODOLOGICAL CHALLENGES}

As noted above, one of the goals of this book is to address the methodological challenges that are hampering our understanding of the human capital resource at different levels. These challenges deal with some specific theoretical issues whose empirical investigation either did not provide us with convergent evidence or did not clarify adequately the dynamic under investigation. More precisely, among the challenges highlighted above are:

- a closer examination of the effect of human capital, observed through the theoretical lens of individuals' shared experience to clarify whether it is characterized by either a linear or a non-linear effect on organizational performance;

- the investigation of a potential agency conflict between firms' ownership/top management and the meso-managerial level constituted by middle managers, since the former are in charge of deciding whether 
and when human capital should be renewed and the latter should proceed to new human capital integration at the team/unit level;

- an enquiry into the topics characterizing the debate in the human capital resource theoretical domain in order to identify the themes on which scholars from different perspectives are concentrating both conceptual developments and empirical efforts.

With respect to the first challenge, in the previous section we have observed that the dynamics that lead to the generation of higher-order resources (i.e., unit-level human resources) have remained underinvestigated (Ployhart et al., 2014). The extant literature maintains that a promising approach to exploring this topic is the research stream that focuses on shared experience among individuals belonging to the same team or organization. A large number of studies have investigated shared experience among team members as a phenomenon leading to the generation of higher-level resources, thanks to the combination of both cognitive and non-cognitive individual characteristics (see Berman, Down, \& Hill, 2002 for a detailed examination of these studies). Shared experience stems from individual tacit knowledge combined with other team/unit members' individual tacit knowledge to generate new higher-order human resources at the team level. The interaction and the interdependence required to carry out a given task thus lead to the creation of team- or unit-level resources. If observed through this approach, higher-level human resources are no longer just an aggregation of heterogeneous individual characteristics, since they become a more complex phenomenon that links two of the elements suggested by Ployhart and Moliterno (2011), namely: (1) the complexity of the unit's task as a measure of the interdependence and coordination among members needed to complete the task; and (2) enabling states, which takes into account behaviors, cognitive mechanisms, and psychological states. These two elements affect the ability of the firm to generate human resources at team or unit level and, in turn, to make these resources viable sources of competitive advantage.

However, notwithstanding the distinguished contributions so far available, the extant research has not yet reached convergence with regard to the effects of higher-level resources on firm performance, especially concerning the dynamic of this effect (i.e., a linear vs a non-linear effect). In particular, some studies suggest a linear relationship between team members' shared experience and firm performance (Reagans, Argote, $\&$ Brooks, 2005), while other scholars maintain a non-monotonic rela- 
tionship, which turns negative after a certain point due to knowledge ossification and predictability (Berman et al., 2002). In addition to the not yet achieved convergence on the effects of shared experience on organizational performance, the examination of these effects carries interesting implications for the renewal choices of human capital and, in particular, on the different actors/subjects interested by these choices that, for the sake of clarity in this volume, we identify with the firm's owner/top management and the middle manager in charge of deploying human capital at the unit/team level. If we assume a non-monotonic relationship (e.g., a non-linear effect that turns negative after a certain point) then the owner/top management must renew periodically and recurrently the bundle of human resources before the team/unit incurs negative results. On the other hand, if the relationship between shared experience and team performance is linear and positive, then renewal processes are infrequently needed and thus these must be carried out only in terms of a planned substitution of those individuals no longer available. Therefore, it is of the utmost importance to clarify whether the relationship between shared experience and performance is either linear or non-monotonic.

With regard to the second challenge, we suggest that it is appropriate to investigate the effect of both internal and external renewal factors (i.e., promotions, demotions, voluntary and involuntary turnover), and also how new human resources with different levels of cognitive and non-cognitive characteristics interact with other human resources already available and embedded at the firm level. This is quite a relevant issue, since the new competences and skills that a given owner decides to introduce within the unit/team is likely to affect an organization's short-term results, with an uncertain effect, perhaps negative. This occurrence, could, in turn, lead a middle manager (i.e., the meso-managerial level in our perspective) in charge of deploying the new human resources to implement a human capital strategy inconsistent with the owner's goal and desideratum.

To the best of our knowledge, to date, the extant research has not paid adequate attention to the meso level, but overlooking this occurrence hampers our understanding of employees' integration and development perception with regard to organizational tenure, job training, and organizational commitment. We maintain that overlooking the meso level constitutes critical neglect, since managers' performance is generally evaluated from a short-term time perspective, thus they could adopt opportunistic behavior if they deem that the top management/owner's human capital policy might negatively affect their unit performance. 
In particular, a middle manager's decisions could negatively affect an owner's renewal policies and long-term strategies because the integration of new employees at the team level (owner's desideratum) may take time to yield the expected performance. As a result, middle managers might decide not to integrate these new resources in the context of a unit's processes to the extent required by the top management/owner. This, in turn, gives rise to an agency problem between the owner (or a given top manager) in charge of human resource renewal and the middle manager in charge of integration and development of human resources. We argue that addressing this issue may provide a quite interesting advance both with regard to macro-meso-managerial-level interactions and a deeper understanding of microfoundations in the context of managerial behavior at different levels of competence (Ployhart \& Hendricks, 2019).

Finally, with regard to the third challenge highlighted above, we investigate the way scholars and researchers are approaching the evolution of the field, with respect, in particular, to its theoretical domain and the relevance of the most recurrent research topic. In particular, we analyze the main topics stemming from the debate on strategic human resources management, with the purpose of identifying a new approach focused on the development of a holistic framework capable of integrating both the micro- and the macro-level perspectives and to take account of the meso-managerial level in the context of human resources management. To this end, we used a data mining approach applied to the analysis of the articles published in the special issue of the Journal of Management (2014), "Strategic human capital: crossing the great divide" (Wright et al., 2014). The abstracts of these articles are reproduced in the appendix at the end of this chapter.

To carry out this analysis we employed a specific methodology, topic development, based on a novel data mining technique, KNIME Analytics, and its related word analysis technique, linear discriminant analysis. By means of these tools, we ran text mining analyses using the most well-known frequency measures of that analysis, that is, inverse document frequency (IDF) and term frequency (TF).

Thanks to this specific word processing methodology and text mining procedure, we constructed a flow chart to highlight the main issues of the debate and the potential ideas/concepts for "crossing the great divide" (Wright et al., 2014).

In Figure 1.3 we report the output of our elaboration using KNIME Analytics Platform 4.0. 


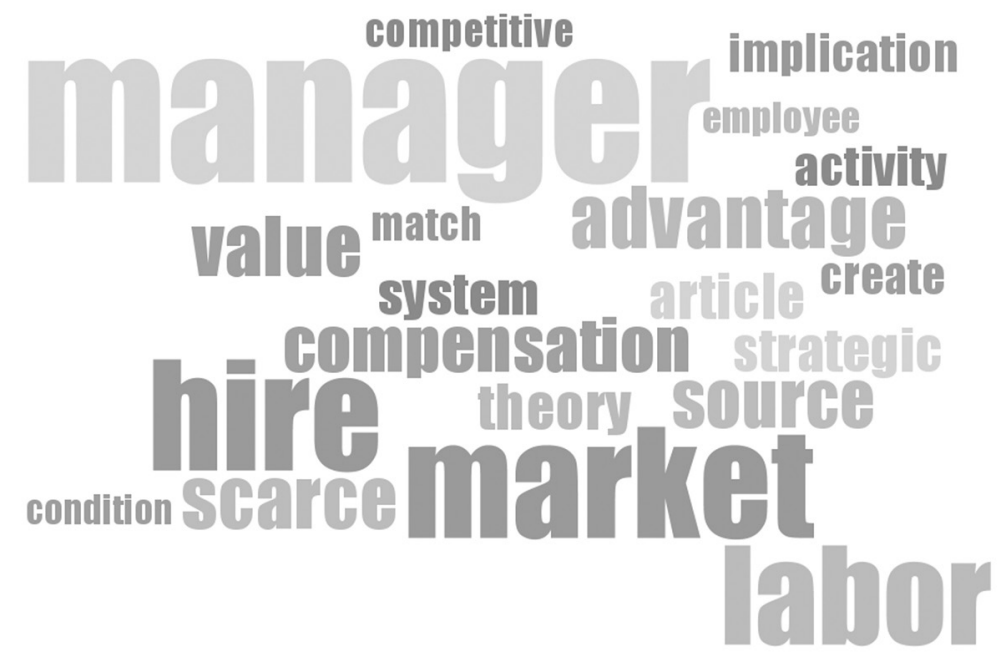

Figure 1.3 Topic modeling on human capital

As shown in Figure 1.3, the word with the highest frequency is "Manager," which implies that this piece of literature seems to pay attention to a meso-managerial level. This is followed by the topics "Hire," "Market," and "Labor," which emphasizes the relevance of the methods adopted to acquire knowledge and skills. The presence of the topic "Compensation" testifies to the attention to HR practices in theoretical studies as well as in empirical efforts, since HR practices focus on the tools employed by managers to improve the contribution of employees to competitive advantage. On the contrary, the topics "Advantage," "Strategic," "Source," although aiming to emphasize the link between human resources and competitive advantage, seem to have received less attention from these contributions.

This invites our reflection on the micro level and the related link between individual characteristics and the performance of a specific task, and the potential relationship of these characteristics with a firm's endowment of knowledge and experience, and, in turn, with competitive advantage. In summary, from the content analysis carried out through 
this novel methodology, it seems that the following points deserve further reflection:

- A new research framework aiming at the reconciliation of the micro and macro levels deserves adequate effort and attention.

- The micro and the macro levels of analysis still appear quite separated in their research goals and theoretical foci.

- The meso level concerning the contribution of middle managers is quite overlooked.

\subsection{CONCLUSION}

The literature on human resources suggests that SHRM is a multifaceted construct made up of both cognitive and non-cognitive characteristics, whose features can be either generic or firm specific, both at the individual or unit level. However, its definition is a necessary, but insufficient condition with which to achieve an advanced and contemporary human resources management conceptual perspective since several research issues should be further investigated, such as:

- the dynamics leading to the creation of higher-order human resources (i.e., either at the team or the unit level);

- how to combine human resources within a given organization with respect to their endowment of both cognitive and non-cognitive abilities;

- how individuals' differences in the endowment of both cognitive and non-cognitive abilities interact;

- how to deal with the different levels of human capital (i.e., micro, meso and macro levels);

- how to manage a potential agency conflict between ownership and meso-managerial level of human resources.

In the following chapters, we take on the challenges highlighted in the previous sections and provide two focused empirical investigations and a novel conceptual framework to deal with the issues reported above. In particular, Chapter 2 endeavors to investigate whether the relationship between shared experience and performance is either linear or non-monotonic, while Chapter 3 examines how human capital renewal choices affect organizational performance and meso-level orientation 
towards cross-level cooperation with regard to human capital development. Finally, Chapter 4 provides a fresh conceptual framework for dealing with strategic human capital at the macro, meso, and micro levels.

\section{NOTE}

1. Realistic, Investigative, Artistic, Social, Enterprising, and Conventional. 


\section{APPENDIX: PAPERS IN THE SPECIAL ISSUE OF THE JOURNAL OF MANAGEMENT (2014)}

Wright, P. M., Coff, R., \& Moliterno, T.P.(2014). Strategic human capital: Crossing the great divide [Editorial]. Journal of Management, 40(2), 353-370.

Strategic human capital has emerged as an area of interest in both the strategy and human resources management literatures, yet these literatures have developed without adequate interdisciplinary conversation. The special issue on strategic human capital sought to bridge this divide through creating a platform for researchers from both fields to engage in dialogue. In addition to commenting on both the journey and destination of the special issue, we explore the manifestations of this divide and identify six issues that emerged that could provide areas of common interest across the two fields.

Ployhart, R. E., Nyberg, A. J., Reilly, G., \& Maltarich, M. A. (2014). Human capital is dead; long live human capital resources! Journal of Management, 40(2), 371-398.

This paper introduces a radically different conceptualization of human capital resources that runs counter to the individual-level approaches that have dominated human capital theory for the last 50 years. We leverage insights from economics, strategy, human resources, and psychology to develop an integrated and holistic framework that defines the structure, function, levels, and combinations of human capital resources. This multidisciplinary framework redefines human capital resources as individual or unit-level capacities based on individual knowledge, skills, abilities, and other characteristics (KSAOs) that are accessible for unit-relevant purposes. The framework and definition offer three broad contributions. First, multidisciplinary communication is facilitated by providing precise definitions and distinctions between individual differences, KSAOs, human capital, human capital resources, and strategic human capital resources. Second, given that human capital resources originate in individuals' KSAOs, multiple distinct types of human capital resources exist at individual and collective levels, and these types are much more diverse than the historical generic-specific distinction. Third, the multiple types of human capital resources may be combined within and across levels, via processes of emergence and complementarity. Consequently, the locus of competitive advantage has less to do with whether human capital resources are generic or specific but instead occurs because nearly all human capital resource combinations are complex, are firm-specific, and lack strategic (or efficient) factor markets. Overall, the proposed multidisciplinary framework opens new avenues for future research that challenge the prevailing literature's treatment of human capital resources. 
Mackey, A., Molloy, J. C., \& Morris, S. S. (2014). Scarce human capital in managerial labor markets. Journal of Management, 40(2), 399-421.

Strategic human capital scholars are increasingly recognizing the importance of human capital scarcity for explaining individual and firm outcomes. This article focuses on scarce human capital in the top manager labor market - and in particular, patterns in which top managers and firms form employment relationships. This examination redirects strategic human capital scholarship in three important ways. First, the findings point to the importance of specifying an omission from prior human capital scholarship: the relationship between human capital and the firm's resource base (e.g., potential complementarities). Second, the article illustrates the need to simultaneously consider both human capital scarcity and complementarities and reinforces that scarce human capital can indeed be general human capital. Finally, the theory explains how complementarities fundamentally alter value creation and appropriation dynamics. Specifically, complementarities facilitate the matching of the best managers and firms with the most productive resources, increase the size of the pie (financial proceeds) from the employment relationship, and can enhance the manager's bargaining power in the division of these proceeds.

Liu, X., Van Jaarsveld, D. D., Batt, R., \& Frost, A. C. (2014). The influence of capital structure on strategic human capital: Evidence from U.S. and Canadian firms. Journal of Management, 40(2), 422-448.

Strategic human capital research has emphasized the importance of human capital as a resource for sustained competitive advantage, but firm investments in this intangible asset vary considerably. This article examines whether and how external pressures on firms from capital markets influence their human capital strategy. These pressures have increased over the past three decades due to banking deregulation, technological innovation, and the rise of institutional investors and new financial intermediaries. Against this backdrop, this study examines whether a firm's capital structure as measured by share turnover, shareholder concentration, and financial leverage is associated with firm investment in strategic human capital. Based on survey and objective financial data from 221 establishments in the United States and Canada, our analysis indicates that firms with greater share turnover, higher shareholder concentration, and higher levels of financial leverage are less likely to invest in human resource systems that create strategic human capital. Differences in national financial systems also lead to differential effects for U.S. and Canadian firms. 
Tzabbar, D., \& Kehoe, R. R. (2014). Can opportunity emerge from disarray? An examination of exploration and exploitation following star scientist turnover. Journal of Management, 40(2), 449-482.

How do the specific characteristics of a departing star influence the effects of the star's turnover on a firm's innovation processes? Proposing a contingency model of key employee turnover, we argue and demonstrate that the individual characteristics of a star scientist who exits a firm determine the effects of the star's turnover for the organization. Based on a longitudinal study of star scientist turnover in the biotechnology industry (1972-2003), we show that while star turnover disrupts existing innovation routines and thus decreases exploitation, this "shock" creates opportunities for the firm to search beyond existing knowledge boundaries, thereby increasing exploration. However, these effects are moderated by the departing star's innovative and collaborative involvement within the firm. Specifically, the results indicate that a departing star's innovative involvement strengthens the negative effects and weakens the positive effects of the star's turnover on exploitation and exploration in the firm, respectively. On the other hand, a departing star's collaborative involvement within a firm strengthens the negative effect of the star's exit on exploitation but increases the positive effect of star turnover on exploration, thereby fostering opportunities for technological renewal. We suggest therefore that the prognosis for firms losing stars may vary, and may not always be dire. Our findings indicate that the short-term and long-term value of human capital is contingent on the social mechanisms surrounding its utilization. Thus, we offer a redirection for research and extend the resource-based view and human capital theory by introducing a resource dependence perspective into this theoretical context.

Brymer, R. A., Molloy, J. C., \& Gilbert, B. A. (2014). Human capital pipelines: Competitive implications of repeated interorganizational hiring. Journal of Management, 40(2), 483-508.

This article offers pipelines as a new perspective on human capital heterogeneity between firms. Using resource-based theory logic, we define pipelines as repeated interorganizational hiring and a practice firms use to differentially acquire and accumulate human capital and mitigate human capital risks. Pipelines are a ubiquitous staffing practice with ambiguous implications for firm performance that to date have eluded scholarly examination. Thus, we use a systems framework to highlight input, output, and process contingencies in which pipeline hiring can create advantage over rivals - contingencies of human capital scarcity in the labor market, the choice of firm activity system, and product market ambiguity (i.e., credence qualities), respectively. Collectively, the article's theoretical foundations provide new insights for human resource, strategy, and human capital fields and open the conceptual space of pipelines for examination by organizational scholars. We discuss the theoretical, empirical, and practical implications accordingly. 
Crocker, A., \& Eckardt, R. (2014). A multilevel investigation of individual- and unit-level human capital complementarities. Journal of Management, 40(2), 509-530.

Human capital theory has recently expanded to include multilevel analysis by conceptualizing the unit-level human capital resource. At the same time, the value of complementary resources has been theorized to provide competitive advantages for firms. Thus, human capital at one level in the firm may impact the performance of human capital at another level in the firm if the resources are complementary. Through a multilevel analysis performed using hierarchical linear modeling of Major League Baseball data, we show that the relationship between individual human capital and individual performance is impacted by complementary functional and managerial unit-level human capital resources. As such, this paper contributes to the understanding of how complementary multilevel human capital resources relate to performance outcomes. Implications of our findings include support for the notion that more is not always better when it comes to high-quality human capital and that unit-level human capital plays an important role in performance of individual-level human capital.

Campbell, B. A., Saxton, B. M., \& Banerjee, P. M. (2014). Resetting the shot clock: The effect of comobility on human capital. Journal of Management, 40(2), 531-556.

In this paper, we examine how employee mobility impacts the human capital of both those who are new to the organization (movers) and those who are existing members (incumbents). Employee mobility events can disrupt both the location-specific and the colleague-specific components of human capital and thus have different impacts on overall human capital. We test our theory on the disparate effects of location change and personnel change on human capital in the highly interdependent context of the National Basketball Association. We find that movers experience adverse performance shocks after mobility events that are moderated when moving as a group, and we also find that group mobility events hinder the performance improvement of incumbents. Our findings are consistent with the limited transfer of location-specific human capital and the disruption of colleague-specific human capital after mobility events.

Khanna, P., Jones, C. D., \& Boivie, S. (2014). Director human capital, information processing demands, and board effectiveness. Journal of Management, 40(2), 557-585.

Research on human capital as a source of competitive advantage has focused largely on firm employees. In this article, we argue that outside directors' general human capital can also be a source of competitive advantage. Firm 
performance is likely to benefit from directors' human capital - that is, their prior experience and education - because such human capital is likely to make them more effective at monitoring management and providing advice. Drawing on insights from research on individuals' cognitive limitations, we further argue that the extent to which the firm is able to benefit from this human capital can be severely limited by the demands for information processing that directors face from their other board positions. Consequently, we find that the benefit of directors' human capital is contingent upon the information processing load placed upon them from their other board appointments. We find support for our hypotheses using data on over 5,700 directors from 650 firms sampled from the Fortune 1000. This study extends the nascent literature on board human capital by showing that in addition to specific expertise in relevant areas, directors' general human capital can also help firms create competitive advantage. The theory developed in this article also contributes to the literature on strategic human capital by incorporating the concept of information processing demands, suggesting that not only do such demands leave limited cognitive capacity for directors to focus on the focal firm but also that they can severely diminish the beneficial effects of directors' general human capital.

Grigoriou, K., \& Rothaermel, F. T. (2014). Structural microfoundations of innovation: The role of relational stars. Journal of Management, 40(2), 586-615.

Conceptualizing new knowledge development as a process of search and recombination, we suggest that a focus on individual productivity alone presents an undersocialized view of human capital. Rather, we emphasize the importance of embedded relationships by individuals to effectively perform knowledge-generating activities. We rely on intraorganizational knowledge networks emerging through individual collaboration to identify actors who can positively influence their organization's knowledge outcomes. We study two types of such relational stars: integrators (outliers in centrality) and connectors (outliers in bridging behavior). We test our ideas using the patenting portfolios of 106 pharmaceutical firms from 1974 to 1998 predicting the effect of relational stars on their firm's quantity and quality of inventive output - proxies for the firm's capacity to develop more and better new knowledge stocks. We find that the presence of relational stars results in firm-level knowledge advantages not only through their own superior recombinant efforts, but also through their capacity to make others around them more effective at knowledge recombination. Relational stars are firm-specific, and their advantages are socially complex and causally ambiguous because they rely on a network of within-firm interactions. Relational stars, therefore, are prime candidates to be a source of sustainable firm-level knowledge advantage. 
Liu, K. (2014). Human capital, social collaboration, and patent renewal within U.S. pharmaceutical firms. Journal of Management, 40(2), 616-636.

Human capital has received much attention as the microfoundation for a firm to achieve competitive advantage. For knowledge-intensive firms, inventors' human capital plays an important role in developing intellectual assets such as patents. Little research, however, has explored how inventors' human capital influences the firm's decisions of which patent to maintain or to abandon. This study investigates the effects of inventors' human capital and collaboration characteristics on patent renewal decisions in the context of U.S. pharmaceutical firms. The results show that having star inventors on the inventor team, having more coinventors, and having inventors from multiple locations significantly increase chances of patent renewal. In addition, having more coinventors positively moderates the effects of star inventors on patent renewal. Implications for research are discussed. 